\title{
FORECASTING OF COMPUTER NETWORK PERFORMANCE WITH QUADRATIC EQUATION
}

\author{
${ }^{1}$ Achmad Ubaidillah, ${ }^{2}$ S. Ida Kholida \\ ${ }^{1}$ Telecommunication of Electrical Engineering, Madura Trunojoyo University, Indonesia \\ 2 Physics Education, Madura Islamic University, Indonesia \\ Email : ca_achmed@yahoo.com
}

\begin{abstract}
The computer network service provider has to observe, evaluate and plan continually its services in order to provide reliable systems. One of the efforts in planning process is forecasting. There are many methods in it, and this paper proposes to use Quadratic Equation Formula as a forecasting method. It is used because of the simplicity and it is suitable to solve problems with parabolic characteristic that can not be solved by linier computational method. It also compares characteristic of Quadratic Equation Formula with Linear Regresion forecasting. The result of this research shows that the computer network performance can be forecasted with Quadratic Equation Formula which has similar case characteristic with it. The standard deviation error of forecast value of the Quadratic Equation Formula is 370 of 3080 forecasted throughput maximum value. While the standard deviation error of forecast value of the linear regresion method is 282 of 3518 forecasted throughput maximum value. But in the forecasted throughput of linear regresion methhod, the output value will allways increase as the increasing of the input variable value. As the result, the error distribution calculation is not interesting anymore because there is no peak value for the forecasted result.
\end{abstract}

Keywords : Forecasting, Computer Network Performance, Quadratic Equation

\section{INTRODUCTION}

There are many advantages of computer network system like resource sharing, reliability, economical side, scalability and communication medium. Madura Trunojoyo University that apply computer network system has to takehold and maintain its system in order to gain the advantages especially with good monitoring, evaluation and planning continually. It is very important to give quality of service of network system to the users in university, especially when the users of computer network in campus increase (Achmad Ubaidillah et al, 2014).

The observation, evaluation and planning of computer network performance are very important to be implemented. There are many research that concern about it. For example, the research that make network planning to define QoS Metric based on total delay and packet loss with Calculus Theory approach on chip modeling architecture (salem Nasri, 2011). Dhobale J.V., Kalyankar N.V., and Khamitkar S.D., observe and evaluate the computer network performance using OMNET++ simulation environment with different input variable (Dhobale J.V. et al, 2014). Other research that concerns in computer network performance are the research that makes remaster of Ubuntu to observe the computer network performance (Andi Pebriananta et al, 2011), the research that measures the computer network performance to manage the availibility (Sri Wulandari et al, 2011), and the research that measures and analizes the distributed computer network performance with different properties for administration (Amit Kumar Sahu et al, 2012).

Beside that, the management of computer network performance can be observed by optimizing and improving the performance. For exmple the research that proposes some recomendations that can improve the network performance based on QoS changes (Winarno Sugeng et al, 2015), The research that combines the MBAC and PBAC to improve admission control and network utilization efficiency (Suleiman Y. Yerima,
2011). Other researchs that develop the improvement of network performance are paper that proposes to improve end to end delay of network management system using network coding (El Miloud Ar Reyouchi et al, 2013), the research that proposes to minimize trannsmission cycle delay between mobiles moving by changing the BEB Algorithm (Ibrahim Syed Ahmad et al, 2013), and the research that proposes to improve TCP Performance over wireless network with frequent disconnections (Purvang Dalal et al, 2011).

The observation, evaluation and planning of computer network performance also can be implemented by developing the performance forcasting system with parameters that influence network performance. Paulo Cortez proposes to use Neural Network, ARIMA and Holt Winter to forecast multi-scale internet traffic (Paulo Cortez et al, 2012). While Poo Kuan Hoong proposes to forecast the network computer traffic using ARMA (Poo Kuan Hoong et al, 2012).

Basically, this paper begins from other research especially (Achmad Ubaidillah et al, 2014). It proposes to use linear and multi linear regresion as a forecasting method of computer network performance. But it is just linear computation. It assumes that the output value will increase as the increasing ofinput variable value. It is contradictive compared with characteristic of computer network performance that can increase and decrease after gain the peak value. So this research proposes to use Quadratic Equation Formula to forecast the computer network performance because of the similarity of the output data characteristic.

Network performance can be measured by turn arround time, response time, throughput, goodput, capacity, availability, reliability, delay, jitter, and blocking probability (Mohammad Iqbal, 2012), (Hendrawan, 2006). This research uses sent packets as the input variable and throughput as the output variable. Linear Regresion As Forecasting Method

Regression is one of statistical development model that is used to predict a value of response variable 
based on the variable explanatory (Hendrawan, 2006). Linear regression is the most simple model of regression as linear equation. Basically, linear regression equation is,

$\begin{array}{ll} & y=a+b x+e \\ \text { with, } \quad & x: \text { input variable }\end{array}$

$$
\begin{aligned}
& a: \text { intercept } \\
& b: \text { slope } \\
& e: \text { random error }
\end{aligned}
$$

the correlation value between input variable and output variable must be known before determining the linear regression equation in order to know the relation and the influence of input variable to output variable. The correlation value is shown as,

$$
r=\frac{1}{n-1} \sum_{i=1}^{n}\left(\frac{x_{i}-\bar{x}}{s_{x}}\right)\left(\frac{y_{i}-\bar{y}}{s_{y}}\right)
$$

with, $\quad r$ : Correlation value between input and output variable

$n$ : event

$x_{i}$ : input variabel

$\bar{x}$ : mean of input variable

$S_{x}:$ standard deviasion of input variable

$y_{i}$ : output variable

$\bar{y}$ : mean of output variable

$S_{y}$ : standard deviasion of output variable

The next step after calculating the correlation value is calculating the slope or gradient value of equation with,

$$
b=r\left(\frac{s_{y}}{s_{x}}\right)
$$

Afterwards, the intercept value can be calculated after knowing the slope value with,

$$
a=\bar{y}-b \bar{x}
$$

\section{Quadratic Equation Formula As Forcasting Method}

The formula of Quadratic Equationproduces parabolic graph, and it is the main contemplation of this research. According to (Frank Ayres, JR., 2006), The main formula is,

$$
y=a x^{2}+b x+c
$$
formula:

$$
\text { The steps to make (5) to become forecast }
$$

1. begin from input variable and output data

2. take 3 samples of its coordinate, 1 sample before peak value, 1 sample at the peak and 1 sample after the peak

3. obtain 3 equations in $\mathrm{a}, \mathrm{b}$ and $\mathrm{c}$ by making substitution the 3 samples to (5)

4. compute the 3 equations with elimination and substiution method to obatain the values of $a, b$ and $\mathrm{c}$

5. obtain a new Quadratic Equation whit them

6. make computational forecasting with it

Error calculations of this paper are RMSE (Root Mean Square Error) that is implemented as standard deviation of the error.

$$
\begin{aligned}
& M S E=\left[\frac{\sum_{\mathrm{i}=1}^{\mathrm{n}} \mathrm{e}_{\mathrm{i}}^{2}}{\mathrm{n}-2}\right] \\
& \mathrm{S}_{\mathrm{e}}=\sqrt{M S E}
\end{aligned}
$$

with

\section{METHODOLOGY}

First, this research simulates a computer network system (figure 1) with Network Simulator 2 (NS2). The system is built as a bottle neck network, all nodes $(0,1,4,6,7)$ send packets to node 3 over node 2 . The traffic types are mixed between TCP and UDP. The variable input is total sent packets, while terminal throughput in node 3 is set as network system performance output. Then, the input and output variable values are computed into Linear Regresion Forecasting method and Quadratic Equation Forecasting Formula. The performance computation result of them are compared each other to be concluded which the better is.

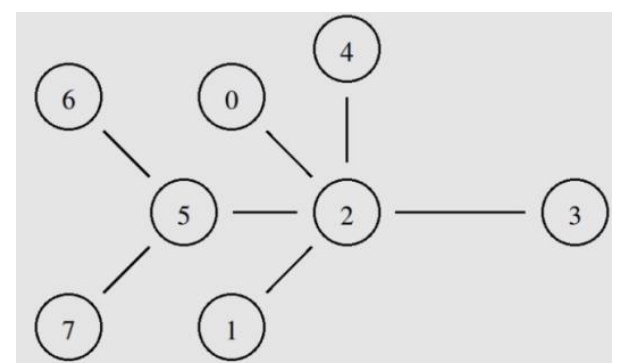

Figure-1. Simulation of computer network system observed

\section{RESULTS} figure 3 .

The simulation results are shown in figure 2 and

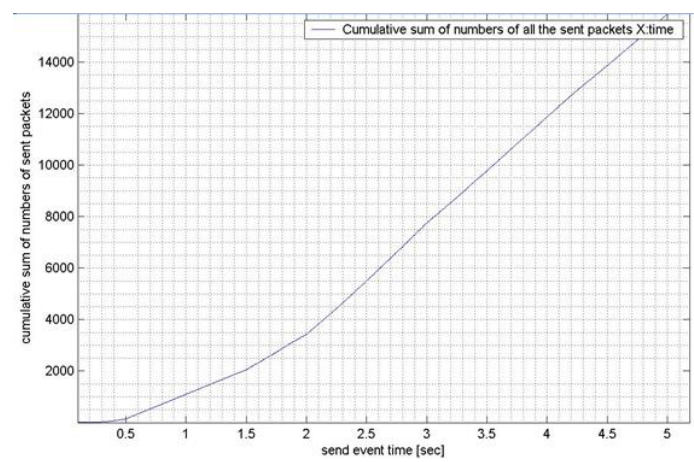

Figure-2. Graph of event time to total sent packets of simulation result

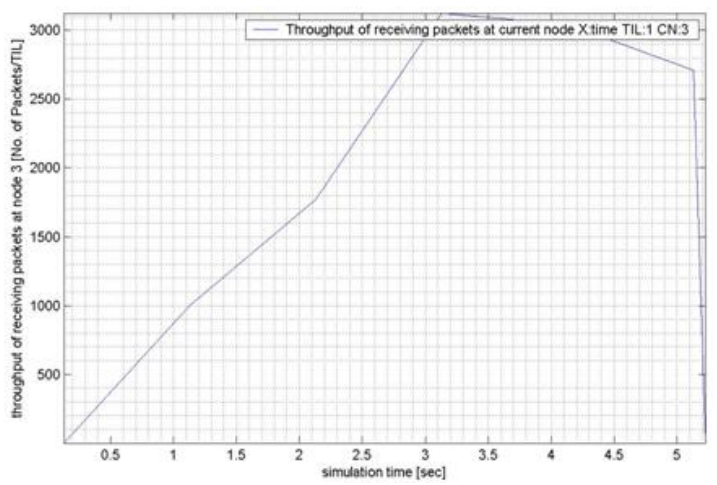

Figure-3. Graph of event time terminal throughput in node 3 of simulation result

Then, the performance resultsare sampled in some node samples shown in table 1 . It shows the correlation between total packets sent and terminal throughput values in node 3 . 
Table-1. Samples of network performance of the simulation and the forecasted value with Linear Regresion method

\begin{tabular}{|r|r|r|}
\hline $\begin{array}{c}\text { Sent_Pckt } \\
\text { (Packets)X }\end{array}$ & $\begin{array}{c}\text { Trhoughput } \\
\text { (Packets/second)Y }\end{array}$ & $\begin{array}{c}\text { Forecasted } \\
\text { Throughput } \\
\text { Y' }\end{array}$ \\
\hline 305 & 370 & 1047 \\
\hline 1230 & 890 & 1195 \\
\hline 2215 & 1297 & 1352 \\
\hline 3490 & 1680 & 1556 \\
\hline 5510 & 2295 & 1880 \\
\hline 7750 & 2944 & 2238 \\
\hline 9726 & 3102 & 2554 \\
\hline 1198 & 3005 & 2915 \\
\hline 1 & 2928 & 3211 \\
\hline 3 & 2720 & 3518 \\
\hline 1383 & & \\
\hline
\end{tabular}

From $\mathrm{X}$ and $\mathrm{Y}$ oftable 1, some parameters that can be calculated :

$$
\begin{array}{ll}
\text { - } & n=10 \\
\text { - } & \bar{x}=7179 \\
\text { - } & S_{x}=5490 \\
\text { - } & \bar{y}=2123 \\
\text { - } & S_{y}=995
\end{array}
$$

Using (2),

$$
r=0,86
$$

Using (3),

Using (4),

$$
b=0,16
$$

$$
a=998
$$

So, the Linear Regrasion equation that will be used as forecasting equation is,

$$
y=998+0,16 x
$$

The Forecasting values ( $\mathrm{Y}^{\prime}$ ) is obtained by using (16). Then the next step is to calculate error distribution with equation (6) and (7). The MSE value is 79.664 and the standard deviation of error $\left(S_{e}\right)$ is 282 .

Then, this research proposes to use Quadratic Equation formula as forecast method. Three nodes $(\mathrm{X}, \mathrm{Y})$ are taken as samples of the network performance, (5510, 2295), (9726, 3102) and (13833, 2928). By inserting them to Quadratic Equation then it obtains,

$$
\begin{gathered}
\text { computational method. Then, } \\
\qquad \begin{aligned}
a & =-0,000031 \\
b & =0,66 \\
c & =-442,5
\end{aligned}
\end{gathered}
$$$$
30360100 a+5510 b+c=2295
$$$$
94595076 a+9726 b+c=3102
$$$$
191351889 a+13833 b+c=2928
$$

From (17), (18) and (19), value of a, b and c can

\begin{tabular}{|c|c|c|}
\hline $\begin{array}{l}\text { Sent_Pckt } \\
\text { (Packets)X }\end{array}$ & $\begin{array}{c}\text { Trhoughput } \\
\text { (Packets/second)Y }\end{array}$ & $\begin{array}{c}\text { Forecasted } \\
\text { Throughput } \\
\text { Y }\end{array}$ \\
\hline 305 & 370 & -243 \\
\hline 123 & & 327 \\
\hline 0 & 890 & \\
\hline 221 & & 876 \\
\hline 5 & 1297 & \\
\hline 349 & & 1496 \\
\hline 0 & 1680 & \\
\hline 551 & & 2273 \\
\hline 0 & 2295 & \\
\hline 775 & & 2839 \\
\hline 0 & 2944 & \\
\hline 972 & & 3080 \\
\hline 6 & 3102 & \\
\hline 119 & & 3060 \\
\hline 81 & 3005 & \\
\hline 138 & & 2807 \\
\hline 33 & 2928 & \\
\hline 157 & & 2321 \\
\hline 52 & 2720 & \\
\hline
\end{tabular}
be obtained by using Elimination and Substitution

So, the forecasting Quadratic Equation is, $y=-0,000031 x^{2}+0,66 x-442,5$

The result of forecasted throughput $\mathrm{Y}^{\prime}$ is shown in table 2 .
Table-2. Samples of network performance of the simulation and the forecasted Throughput with Quadratic Equation Formula

\section{DISCUSSIONS}

It is interesting to watch forecasted throughput $\mathrm{Y}^{\prime}$ in table 1, that the value will always increase as the increasing of the input variable value. It becomes the main problem and the main weakness of forecasting with linear regresion method. It is not appropriate to be implemented to computer network performance that has parabolic characteristic. Beside that, the error distribution like MSE and $S_{e}$ is not important anymore. While the real throughput value will decrease after peak value, but the forecasted throughput value will always increase. It will cause the error valeu is getting higher and higher as the increasing of input variable.

On the opposite, the result of forecasted throughput $Y^{\prime}$ of Quadratic Equation shown in table 2, shows that the forecasted throughput $Y^{\prime}$ values increase, obtain the peak value then decrease like parabolic graph. It has similar characteristic with values of Y. As the result, error distribution becomes important to be observed. The MSE value is 136.622 and the standard deviation of error $\left(S_{e}\right)$ is 370 of 3080 maximum forecasted throughput value.

\section{CONCLUSION}

From the analysis of the computational result before, it is clearly proven and concluded that Linear Regresion method is not appropriate to be used as forecasting method for computer network performance because of the linearity problem, while network performance has parabolic characteristic. Even, calculation of error distribution is not important anymore because of it. In the other side, Quadratic Equation Formula can be used as forecasting method for computer network performance because of the characteristic similarity. So, for the case like this, Quadratic Equation Formula is better than Linear Regresion method.It can be said the research of this paper 
The error standard deviation of forecasted throughput Y' with Quadratic Equation Formula is not to bad, 370 of 3080 maximum forecasted value or about $12 \%$. It means, there is wide possibility to make it better. So, the suggestion for next research is how to make it better.

\section{REFERENCES}

Achmad Ubaidillah Ms., Koko Joni, Miftahul Ulum, Haryanto, Diana Rahmawati, and Riza Alfita, 2014. Forecasting of Computer Network Performance with Linear and Multi-Linear Regresion Method, FORTEI, ISBN:978-602-9056-70-9.

Amit Kumar Sahu and Naveen Hemrajani, 2012, An Analysis of Distributed Computer Network Administration, International Journal Computer Technology and Applicaton. 3(2) : 660-667.

Andi Pebriananta, Indrastanti R.W., T. Indra Bayu, 2011, Development of Computer Network performannce observer Through Remastering Ubuntu. JUTI 9(1) : 3540 .

Dhobale J.V., Kalyankar N.V., and Khamitkar S.D., 2014, Computer Network Performance Evaluation Based on Different Data Packet Size Using OMNET++ Simulation Environment, International Journal of Advanced Research in Computer Science and Technology vol. 2, issue 2, ver. $1: 91-95$

Dhobale J.V., Kalyankar N.V., and Khamitkar S.D., 2014, Computer Network Performance Evaluation Based on Network Scalability Using OMNET++ Simulation Environment, International Journal Advanced Networking and Application. 5(5) : 2041-2045.

Dhobale J.V., Kalyankar N.V., and Khamitkar S.D., 2014, Computer Network Performance Evaluation Based on Data rate and Number of Clients Per Server Using OMNET++ Simulation Environment, Global Journal Computer Science and Technology : E Network, Web and Security. vol. 14, issue 3, ver. 1.0.

El Miloud Ar Reyouchi, Kamal Ghoumid, Koutaiba Ameziane, and Otman El Mrabet, 2013, The Improvement of End to End Delays in Network Management System Using Network Coding, International Journal Computer Network and Communication. 5(6) : 65-84.

Frank Ayres JR., 2006, Schaum : University Mathematics (Third Edision), Erlangga

Hendrawan, Dr., 2006, Handout : Introduction of Telecommunication and Computer Network Performance, Electrical Engineering of Bandung Technology Institute

Hendrawan, Dr., 2006, Handout : System Comparison and Forecasting, Electrical Engineering of Bandung Technology Institute

Ibrahim Sayed Ahmad, Ali Kalakech, and Seifedine Kadry, 2013, Minimizing Mobiles Communication Time
Using Modified Binary Exponential Backoff Algorithm, International Journal Computer Network and Communication. 5(6) : 85-102.

Mohammad Iqbal, Dr., 2012, Handout : System Performance Analysis, Gunadarma University

Paulo Cortez, Miguel Rio, Miguel Rocha, and Pedro Sousa, 2012, Multi-Scale Internet Traffic Forecasting Using Neural Network and Time Series Methods, Expert System. 29(2) : 143-155.

Poo Kuan Hoong, Ian K.T. Tan, and Chee Yik Keong, 2012, Bit Torrent Network Traffic Forecasting with ARMA, International Journal Computer Network and Communication. 4(4) : 143-156.

Purvang Dalal, Nikhil Kothari, and K.S. Dasgupta, 2011, Improving TCP Performance Over Wireless Network with Frequent Disconnections, International Journal Computer Network and Communication. 3(6) : 169-184.

Salem Nasri, 2011, Network on Chip : A New Approach of QoS Metric Modeling Based on Calculus Theory, International Journal Computer Network and Communication. 3(5) : 53-60.

Sri Wulandari and Achmad Affandi, 2011, Measuring of Computer Network Service Performance for Management of availability, SESINDO, Department of Information System of ITS

Suleiman Y. Yerima, 2011, Implemetation and Evaluation of Measurement Based Admission Control Schemes within a Converged Networks QoS Management Framework, International Journal Computer Network and Communication. 3(4) : 137-152.

Winarno Sugeng, Jazi Eko Istiyanto, Khabib Mustofa, and Ahmad Ashari, 2015, The Impact of QoS Changes Towards Network Performance, International Journal Computer Networks and Communications Security. 3(2) : 48-53. 